\title{
Immigrant Status as an Influential Factor in Additional Language Learning: A Comparison of French Language Achievement of Canadian-born Monolinguals, Bilinguals and Bilingual Immigrants
}

\author{
Callie Mady \\ Nipissing University, North Bay, ON, Canada
}

\begin{abstract}
This study compares the French as a second language achievement of Canadian-born Englishspeaking students, Canadian-born bilingual students and bilingual immigrant students as gathered by means of a multi-skills FSL test. In addition, it seeks to explain the differences in performance by investigating the impact of a variety of influential factors that have been previously identified in the literature to date: L1 use and context of learning for bilingual groups, motivation, attitude, willingness to communicate, metalinguistic awareness and strategy use for all groups.
\end{abstract}

Index Terms - second language teaching, additional language learning, multilingual language acquisition, second language acquisition

\section{INTRODUCTION}

When comparing second and subsequent language acquisition, researchers have recognized that the same variables that influence second language (L2) acquisition also impact additional language (Ln) learning. Among numerous influential factors, proficiency in language (s) known (Cummins, 1979), context (s) of language acquisition (Gibson \& Hufeisen, 2003), language distance (s)(De Angelis, 2007), perceived distance (Kellerman, 1978) and motivation and attitudes (Ushioda \& Dörnyei, 2012) impact language learning. Although the factors above impact Ln learning, it is prior experience with two languages that is the unique, complex factor differentiating second from Ln learning. Although there are exceptions (e.g., Balke-Aurell \& Lindblad, 1983), many studies have shown knowledge of an L2 to have a positive impact on Ln learning under certain conditions (e.g., Hart, Lapkin, \& Swain, 1988; Cenoz \& Valencia, 1994).

The underlying support for L2 knowledge enhancing Ln learning is grounded in Cummins (1979) interdependence hypothesis, which highlights the common underlying mental processes that accumulate with language learning experience. Similarly, Cook's (1995) more recent multicompetence model recognizes languages and interlanguage(s) as adding to the linguistic knowledge and skills of an individual. This model highlights the potential for all language knowledge to be accessed as a resource for further learning. More specifically, Cook underscores that the metalinguistic knowledge that comes with knowing two or more languages is advantageous for Ln learning. Learners can benefit from this underlying knowledge of the abstract structure of language regardless of the particular language being learned (Bialystok, 2001). Although Berthoud (2003) claims that Ln learning is in and of itself metalinguistic because it encourages a comparison of languages, researchers (e.g., Castelotti \& Moore, 2005; Moore, 2006) argue that learners must pay explicit attention to such knowledge (i.e., activate their metalinguistic awareness), in order to reap the rewards.

The terms "metalinguistic knowledge" and "awareness" in Ln learning research often refer to the transfer of linguistic knowledge and/or skills across languages (Cazden, 1974). Such knowledge and the consciousness of such knowledge have been credited with benefitting bilinguals in Ln learning. In her description of the DST model of Multilingualism, Jessner (2008a) claims that metalinguistic awareness (which she defines as a set of skills and abilities that the multilingual user develops as a result of his/her own prior linguistic and metacognitive knowledge) is a key factor in bilingualism being an advantage in other language learning. At times, researchers hypothesize that advanced metalinguistic awareness is a positive factor in Ln learning (e.g., Peyer, Kaiser, Berthele, 2010), whereas in other studies, the impact of metalinguistic awareness has been directly tested and analysed through the research design. Cenoz and Valencia (1994), for example, compared English test results and hypothesized that the advantages of their Spanish/Basque bilingual group as compared to those of a monolingual group of university students was due to heightened metalinguistic awareness. In his study of 252 bilingual students studying English in Grades 5 and 8, Lasagabaster (1998) directly tested students' language proficiencies 
and their metalinguistic knowledge to find that proficiency positively correlated to metalinguistic knowledge- the higher proficiency the higher level of metalinguistic knowledge. In a subsequent analysis of the same data set, Lasagabaster (2001) examined the role of metalinguistic awareness in the development of English reading, writing, listening and speaking skills. Through correlational analysis, he found metalinguistic awareness to be related to all language skills. In further analysis done with regression analysis, he found metalinguistic awareness to be positively linked to reading in both classes and writing for the Grade 8 group. In another explicit examination of the impact of metalinguistic awareness, Perales and Cenoz (2002) tested adult students' $(n=441)$ proficiency in Basque and their metalinguistic awareness to discover, using regression analysis, that metalinguistic awareness was one of the best predictors of oral and written proficiency. Clyne, Hunt, \& Isaakidis (2004), too, in their observations of 44 students learning an Ln-Greek or Spanish, found that bilingual students outperformed monolinguals in terms of grades and the frequency of oral participation observed. They also determined that the bilingual students were more proficient at explaining their metalinguistic knowledge.

Jessner (1999) includes language-learning strategies as part of the enhanced metalinguistic awareness of bilinguals learning an Ln. In her study of bilinguals learning an Ln, through think-aloud protocols, Jessner examined learners' strategy-use, highlighting the use of strategies as a compensatory skill. She suggests that perceived language distance influences the degree to which learners will access such metalinguistic knowledge and encourages teachers to make such knowledge explicit to learners. In a more recent publication, Jessner (2008a) purports that use of metalinguistic knowledge may also be enhanced with prior formal language learning experience. In support of this assertion, Ibarraran, Lasagabaster and Sierra (2008) go so far as to suggest including metalinguistic awareness training as part of the curriculum with a view to improving students' attitudes toward learning other languages. Similar to Jessner, in his examination of Ln reading, Bruno (2001) found that Ln learners to use strategies to compensate for limited Ln knowledge. Kemp (2007), by means of a questionnaire, also examined the strategy use of bilingual and multilingual participants $(n=144)$, and discovered that the more languages the participants knew the greater number of strategies they use and the more frequently they use them. However, Geldersen, Schoonen, De Glopper, Hulstijn, Snellings, Simis, Stevenson (2003) found that strategy use was not able to compensate for low reading proficiency in their study of bilingual and multilingual Dutch students, which showed the bilinguals outperforming the multilingual students.

Even though, in general, the studies above highlight the potential for metalinguistic awareness to enhance Ln learning under certain linguistic conditions, others suggest that it is more likely that metalinguistic knowledge is used when it has been explicitly highlighted by a teacher for example. Singleton and Aronin (2007) agree that multilinguals have more affordances than bilinguals or monolinguals but that they must be aware of such affordances to be able to use them. For example, a multilingual needs to be aware of commonalities in order to transfer items from one language to another, indeed often choosing the language of transfer when more than one language is known. Similarly, in her investigation of children interpreting texts in unknown languages, Moore (2006) concludes that accessing language knowledge as a resource is context-dependent and happens more frequently in a school setting that acknowledges all languages as resources. Likewise, Castelotti \& Moore (2005) suggest that the likelihood of learners benefitting from prior language knowledge is dependent upon the curriculum highlighting commonalities between languages, encouraging learners to reflect upon their learning and having frequent opportunities to use those skills within the class. In fact, Moore's work with Castelotti (2005) suggests that explicitly drawing learners' attention to strategies can also be beneficial to monolinguals. Europe has taken the lead in making these types of commonalities evident with its European Comprehension project (Eurocom Centre, 2003) whose goal is to give citizens of common language background (e.g., romance language) knowledge to understand each other through inferencing. They claim that making commonalities between languages evident heightens the learners' ability to access their prior language knowledge themselves.

\section{METHODOLOGY}

This study compares the French as a second language ${ }^{i}$ (FSL) achievement of Canadian-born English-speaking students (CBE), Canadian-born bilingual students (CBB) and bilingual immigrant students (IMM) as gathered by means of a multi-skills FSL test. In addition, it seeks to explain the differences in performance by investigating the impact of a variety of influential factors that have been previously identified in the literature to date: L1 use and context of learning for bilingual groups, motivation, attitude, willingness to communicate, metalinguistic awareness and strategy use for all groups. For the purpose of this study, metalinguistic awareness is the set of skills or abilities multilingual users develop owing to their prior knowledge (Jessner, 2008a, p. 275). In particular, this study explores the explicit use of this awareness as identified by the use of strategies-production, reception and use of prior language knowledge.

\section{Research questions and hypothesis}

In general, this study sought to explore factors that influenced French test outcomes and in particular it examined if and how metalinguistic awareness impacted French achievement across the groups. Previous research, as cited above, led to the hypothesis that multilingual students would have heightened metalinguistic awareness and that would have a positive impact on test results. 


\section{Study Context}

This study was conducted in Canada in the "English-dominant" province of Ontario. Ontario is the Canadian province that receives the most immigrants. The local context of this study is an urban area where the immigrants form approximately 48 per cent of the population (Statistics Canada, 2006). It would be extremely rare for students to be exposed to French in the community. The data were collected from two schools in the region. The language of instruction in the schools is English. The students, however, study French once a day for approximately forty minutes. The students in this study were in Grade 6 and in their second year of obligatory French study.

\section{Participants}

The participants for this study were eleven years of age and came from eight different classes in two different schools. Each school contributed participants to each of the three groups. This paper presents the results of a smaller data set from that of the larger study — a data set from three groups of participants of similar size (i.e., 23 CBEs, 23 CBBs and $22 \mathrm{IMM}$ ). The CBE and CBB groups were randomly selected from the larger group whereas all the IMMs were included. The IMM group in this study was comprised of students born in Southern Asia (60\%), Africa (13\%) Southeast Asia (4\%), Southern Europe (4\%), and Central Asia (4\%) who had come to Canada during their elementary school years. The remaining participants' country of origin was unknown. The students' languages of origin were from a variety of language families-excluding romance languages. They self-assessed their English skills to be on par with the other two groups, although some students required English language support as determined by a board specialist. Similarly, the CBB group's L1/heritage language (s) were from a variety of language families other than romance (e.g., Indo-Aryan, Afro-Asiatic). None of the participants had previous experience with French before beginning its study in Grade 4.

\section{Instruments}

\section{Questionnaire.}

The questionnaire designed for this study was created to explore a variety of potential influencing factors on participants' Ln achievement. The first section contained Likert-scale items pertaining to language anxiety (6 items), willingness to communicate in class (17), attitudes toward the learning situation, integrative motivation (10), motivation to learn FSL (8) and languages in general (3) as well as items on metalinguistic awareness (9). The metalinguistic section was limited to prior language (e.g., using similarities between languages to guess word meanings) and strategy use (e.g., finding and correcting mistakes). The second section required students to self-assess their French, English and, where applicable, other language knowledge and use. The last section requested their demographic information. The questionnaire was divided into 3 sections all of which were completed online, during class time in one sitting, and under the supervision of the students' FSL teacher during a 40-minute class. The questionnaire was piloted with a Grade 6 class before use in the study.

\section{Observations.}

Each of the two classes was observed on five occasions for an approximate total of 200 minutes per class. Field notes were kept during each observation with attention to language use. In particular, observations were used to determine if teachers made explicit reference to use of prior language knowledge as a means of enhancing French learning.

\section{FSL test.}

A four-skills test-listening, speaking, reading and writing, was used to determine students' FSL proficiency. The test was comprised of sections of the Diplôme d'études en langue française (DELF, A1, primaire) (Centre international d'études pédagogiques, 2012), which were deemed to be appropriate through pilot testing with the same grade prior to use. Due to time constraints of the classes the listening, reading and speaking components were reduced to two parts per skill. A sub-group of randomly selected CBBs $(n=23)$ completed the speaking component whereas, due to lesser numbers, all available IMMs and CBEs participated in the oral test. Both of the listening sections were too easy to determine group differences and are therefore not part of the findings reported below.

\section{Data Reduction}

The first set of variables condensed were those related to the FSL test variables, which were presented in raw data as two reading subtests, two writing subtests, and five speaking scores from two subtests. The second set of variables was items on the student questionnaire where multiple items were constructed to represent a single construct. Data reduction methods were adopted to create these composite variables. The data reduction method adopted was principal components analysis (PCA). As an element of construct identification was required for student questionnaire variables, factor analyses were also conducted as a secondary analysis in order to be sure findings were credible. Factor analyses (using principal axis factoring) produced similar results to the PCA analyses, and are not reported. When defining new variables, the process started with the author's initial theories about represented constructs, and then added and removed variables as the criteria supported or rejected items (i.e., items chosen to measure metalinguistic awareness were verified to determine whether they could remain as part of the final construct). In order to facilitate readability, the French composite scores were multiplied out using the following equation: Score $=50+10 \mathrm{PCA}$. Therefore for French composite scores, the means are 50 and the standard deviations are 10.

Having determined acceptable correlations, composite variables were formed for the reading, writing and speaking test components. For the student questionnaire, the previously identified metalinguistic awareness variable showed two 
factors: metalinguistic awareness and cognitive strategies. These factors were used as individual variables in the analyses. As these variables were predictor variables, they were not multiplied out and each variable has a mean of 0 and a standard deviation of 1 . The composite variables are presented in Table 1.

TABLE 1:

COMPOSITE VARIABLES FOR USE IN ANALYSES

\begin{tabular}{ll} 
& COMPOSITE VARIABLES FOR USE IN ANALYSES \\
\hline French measures & Student questionnaire \\
\hline Reading & Integrative, motive \\
Writing & Integrativeness, climate \\
Speaking & Motivation to continue to learn French \\
& Attitude toward learning French \\
& Anxiety \\
& Willingness to communicate \\
& Metalinguistic awareness \\
& Cognitive strategies \\
& Language of origin: Speaking skills \\
& Language of origin: Literacy skills \\
\hline
\end{tabular}

\section{RESUlTS AND ANALYSIS}

One-way ANOVAs were conducted to identify whether statistically significant differences existed in FSL achievement among groups. Given the small size of the IMM group $(n=23)$ and with the view of having equal groups, a random sample of 23 participants was selected from the other two groups: CBE and CBM.

Analysis of Variance

As can be seen from Table 2, significant differences were found on the writing and speaking scores. Significant differences among the groups were found on writing scores, $F(2,42)=6.10, p<0,05$, partial $\eta^{2}=.15$ and speaking scores, $F(2,65)=6.48, p<0.05$, partial $\eta^{2}=.17$. Regarding effect sizes, $\eta^{2}$ values, small=.01, medium=.06 and large $=.14$. As per the effect sizes, the significant differences range from medium to large.

TABLE 2:

ANOVA RESULTS FOR LANGUAGE GROUPS

\begin{tabular}{llll}
\hline Score & df & $\mathrm{F}$ & partial $\eta^{2}$ \\
\hline Reading score & 2,65 & 2.86 & .08 \\
Writing score & 2,42 & $* * 6.10$ & .15 \\
Speaking score & 2,65 & $* * 6.48$ & .17 \\
\hline$* * *=\mathrm{p}<.001 ; * *=\mathrm{p}<.01 ; *=\mathrm{p}<.05$ & & &
\end{tabular}

Dunnet's C was selected as the post-hoc test because it does not assume homogeneity of variance, and although Levene's test failed to report heterogeneity of variance, the relatively small sample sizes in this study may have rendered heterogeneity non-visible. Therefore post-hoc tests require a conservative estimate of significance.

As shown below in Table 3, the post hoc tests revealed the IMMs and CBBs $(M=51, S D=10.06)$ and $(M=55.1, S D$ $=6.97)$ to outperform the $\mathrm{CBE}(M=45.4, S D=11.31)$ on the Writing domain. As it pertains to the speaking score, the IMMs $(M=57.5, S D=9.00)$ significantly outperformed the CBE $(M=47.8, S D=9.61)$ by nearly a full standard deviation.

TABLE 3:

\begin{tabular}{lllllll}
\multicolumn{7}{c}{ DESCRIPTIVE STATISTICS AND POST-HOC TESTS FOR EACH SCORE } \\
\hline Score & Language Group & Mean & sd & N & \multicolumn{2}{c}{$95 \%$ confidence interval } \\
& & & & & CBE & CBB \\
\hline Reading score & CBE & 50.4 & 9.60 & 23 & & \\
& CBB & 49.7 & 9.45 & 23 & & \\
\multirow{5}{*}{ Writing score } & IMM & 55.8 & 9.20 & 22 & & \\
& CBE & 45.4 & 11.31 & 23 & & \\
& CBB & 51.0 & 10.06 & 23 & $*-9.86$ to -.11 & \\
Speaking score & IMM & 55.1 & 6.97 & 22 & $*-14.65$ to -3.08 & -81 \\
& CBE & 47.8 & 9.61 & 23 & & \\
& CBB & 50.7 & 9.32 & 23 & -9.94 to 4.09 & \\
& IMM & 57.5 & 9.00 & 22 & $*-16.75$ to -2.79 & -13.72 to .09 \\
\hline
\end{tabular}

*An asterix indicates that the $95 \%$ confidence interval does not contain zero, and therefore the difference in means is significant at $\mathrm{p}<.05$ using Dunnet's C procedure

\section{Multiple Regression Analyses}

In order to determine the impact of student grouping (i.e., CBB, CBE, and IMM) while controlling for other factors, multiple regression analyses were conducted on each FSL composite score while controlling for gender (Boy), class, identification of needing learning support (ILS) and identification of requiring English as a second language (ESL) support using the enter method. Each model explained a significant amount of the variance. The predictor variables in this model accounted for $22 \%$ of the variance in the Reading Scores, $F(6,139)=7.73, p<0.001,52 \%$ of the variance in 
the Writing Scores, $F(6,1396=26.69, p<0.001$, and $45 \%$ of variance in the Speaking Scores $F(6,109)=16.35, p<$ 0.001 (see Table 4).

TABLE 4:

MODEL SIGNIFICANCE TESTS

\begin{tabular}{lllll}
\hline Dependent variable & $\mathrm{R}^{2}$ & $\begin{array}{l}\text { Adjusted } \\
\mathrm{R}^{2}\end{array}$ & $\mathrm{~F}$ & $\begin{array}{l}\text { degrees of } \\
\text { freedom }\end{array}$ \\
\hline Reading*** & .25 & .22 & 7.73 & 6,139 \\
Writing*** & .54 & .52 & 26.69 & 6,136 \\
Speaking $* * *$ & .47 & .45 & 16.35 & 6,109 \\
\hline \multicolumn{4}{c}{$* * *=\mathrm{p}<.001 ; * *=\mathrm{p}<.01 ; *=\mathrm{p}<.05$ (two-tailed test) }
\end{tabular}

The regression coefficients are reported in Table 5 below. As it pertains to student groups, being in either the CBE or the CBB group did not prove to be a significant predictor of results. Being part of the IMM group, however, is significantly advantageous on the Reading and Speaking tests. IMMs were predicted to score an extra 5.37 points on Reading and an extra 5.83 points on Speaking. As the standard deviation for the composite scores is 10 points, these benefits equate to half a standard deviation of improvement, representing a substantial benefit. It is worth noting that being part of the IMM group remained advantageous when controlling for other variables whereas the other two groups were not shown to be predictors of FSL test scores. Given the focus of this paper, also deserving of attention, as it pertains to English proficiency, is the finding that although those students who required ESL support would experience a disadvantage with a reduction in scores, the advantage of being in the IMM group outweighed the disadvantage of requiring ESL support ${ }^{\mathrm{ii}}$.

TABLE 5:

REGRESSION COEFFICIENTS FOR STUDENT GROUP MEMBERSHIP ON EACH MEASURE OF FRENCH ACHIEVEMENT

\begin{tabular}{llllllllll}
\multicolumn{8}{c}{ REGRESSION COEFFICIENTS FOR STUDENT GROUP MEMBERSHIP ON EACH MEASURE OF FRENCH ACHIEVEMENT } \\
\hline & Intercept & Boy & CBB & IMM & Class & ILS & ESL & N & Adjusted R \\
\hline Reading pca & $* * * 51.16$ & $* * *-6.30$ & 0.08 & $* 5.37$ & $* 4.33$ & $*-5.07$ & -3.11 & 146 & 0.22 \\
Writing pca & $* * * 45.60$ & $* * *-5.43$ & 0.05 & 1.98 & $* * * 12.67$ & $* * *-11.46$ & -2.4 & 143 & 0.52 \\
Speaking pca & $* * * 45.91$ & $*-3.45$ & 0.64 & $* 5.83$ & $* * * 11.52$ & $* * *-9.28$ & -3.77 & 116 & 0.45 \\
\hline \multicolumn{8}{c}{$* * *=p<.001 ; * *=p<.01 ; *=p<.05$ (two-tailed test) } & &
\end{tabular}

For pca composite scores, mean $=50$, standard deviation $=10$

Additional multiple linear regression analyses were conducted for each composite score on the FSL test to identify affective and linguistic factors that are statistically significant predictors of FSL test scores as communicated in responses to the questionnaire.

Table 6 reports the regression coefficients for each dependent variable that indicate the relative added value of each significant predictor variable for that dependent variable.

The strongest predictors for FSL achievement across measures were: (a) how often students speak French with friends outside class, (b) how often they speak French in class, (c) anxiety levels, (d) metalinguistic awareness, and (e) hearing French outside of class. For all the variables except metalinguistic awareness, higher values on the variables were associated with higher scores. That is to say, the greater the amount of French exposure and use in and outside of class, and the greater the anxiety the higher the scores. Metalinguistic awareness (i.e., use of prior language knowledge as determined by the questionnaire), however, was found to be associated with lower scores while cognitive learning strategies, diverse forms of motivation, and willingness to communicate were all not predictors of FSL achievement. In particular, metalinguistic awareness actually resulted in decreased levels of the speaking score by 1.69 points.

TABLE 6:

REGRESSION COEFFICIENTS FOR STUDENT FRENCH LANGUAGE ATTITUDES AND EXPERIENCES ON EACH MEASURE OF FRENCH ACHIEVEMENT

\begin{tabular}{llll}
\hline & Reading pca & Writing pca & Speaking pca \\
\hline Intercept & $* * * 40.54$ & $* * * 29.54$ & $* * * 46.39$ \\
French with friends & $* 1.74$ & $* * 2.12$ & $* * 2.14$ \\
French in class & $* 1.83$ & $* * * 2.55$ & - \\
Integrative motive & - & - & - \\
Integrative Canada & $\mathrm{X}$ & - & - \\
Motivation to continue & $\mathrm{X}$ & $\mathrm{X}$ & $\mathrm{X}$ \\
Attitude & $\mathrm{X}$ & $\mathrm{X}$ & $\mathrm{X}$ \\
Anxiety & - & - & $* * * 4.22$ \\
Willingness & $\mathrm{X}$ & $\mathrm{X}$ & $\mathrm{X}$ \\
Metalinguistic & $\mathrm{X}$ & - & $*-1.69$ \\
Awareness & & & \\
Strategy use & - & - & - \\
French music & $\mathrm{X}$ & $\mathrm{X}$ & $\mathrm{X}$ \\
French website & - & - & - \\
Visited French country & $\mathrm{X}$ & $\mathrm{X}$ & $\mathrm{X}$ \\
Heard French outside & - & $* 3.99$ & - \\
$\mathrm{N}$ & 132 & 130 & 102 \\
Adjusted $\mathrm{R}^{2}$ & .10 & .34 & .42 \\
\hline \multicolumn{2}{c}{$* * * \mathrm{p}<.001 ; * * \mathrm{p}<.01 ; *=\mathrm{p}<.05$ (two-tailed test) }
\end{tabular}

For pca composite scores, mean $=50$, standard deviation $=10$ 
It is interesting to note that use of French in and outside of class were significant predictors of higher French achievement. This in combination with the fact that metalinguistic awareness - that focused exclusively on use of prior language knowledge, is associated with lower achievement hints at the importance placed on using the target language. In fact, the intergroup comparisons showed metalinguistic awareness to be associated with lower achievement and lower achieving groups relied on this awareness more often.

\section{Comparison of Two Bilingual Groups' Language Experiences}

Given that use of metalinguistic knowledge can be enhanced by previous formal language learning (Moore, 2006), in addition to the fact that it was the two bilingual groups that, at times, outperformed the CBE group, I conducted Wilcoxon-Mann Whitney tests to investigate whether frequency of use of L1/heritage language, of English or the contexts of learning their L1s/heritage language or English impacted results. No significant results were found when the Wilcoxon-Mann Whitney tests were carried out, indicating that no significant differences between the bilingual groups were related to scores on L1/heritage language or English use nor context (s) of their acquisition (see Table 7).

TABLE 7:

SIGNIFICANCE TEST RESULTS FOR WILCOXON-MANN WHITNEY TESTS

\begin{tabular}{lllll}
\hline Variable & $\mathrm{N}$ & $\mathrm{z}$ score & $\begin{array}{l}\text { Effect size } \\
(\text { mean ranks) }\end{array}$ \\
\hline & & & CBB & IMM \\
Use of L1 & 103 & -.38 & 52.31 & 50.63 \\
Use of English & 104 & -.10 & 52.63 & 51.92 \\
Context of English learning & 104 & -.65 & 51.53 & 56.39 \\
Use of L1 at home & 104 & -.30 & 52.19 & 53.87 \\
Context of L1 acquisition & 104 & -1.12 & 51.03 & 59.08 \\
\hline$* * * \mathrm{p}=<.001 ; * \mathrm{p}=<.01 ; * \mathrm{p}=<.05$ & & &
\end{tabular}

In summary, as it pertains to comparing the FSL scores among the three groups, the IMMs outperformed the CBEs on writing and speaking and the CBB group outperformed the CBE group on writing. In the subsequent analyses taken to better understand those results, regarding the impact of various groups, among other variables (i.e., being in one class over another) being part of the IMM group advantaged reading and speaking scores. Examination of the linguistic and affective variables as gathered through the questionnaire, suggested use of French and anxiety (linked to speaking) as advantageous, whereas metalinguistic awareness was disadvantageous to writing. Upon exploration of additional factors as they pertained to the two bilingual groups, the Wilcoxon Mann Whitney tests did not identify use or context of acquisition of L1/heritage language (s) as being influential factors.

\section{Observations}

Field notes kept during the observed classes-five per school, indicate an almost exclusive use of French in one school and a frequent use of English in the other on the part of both students and teachers. It is worth noting that while French and English were languages shared by the students and the teachers, in one school the teacher also shared a common heritage language with the students, but did not make reference to other languages in the observed period. No explicit reference to English was not made with the view to encouraging students to use their language knowledge to improve their French learning.

\section{DiSCUSSION AND CONCLUSION}

Congruent with other research, the bilingual groups in this study outperformed the monolingual group on certain test components. However, contrary to other research (De Angelis, 2007), superior results were not due to enhanced metalinguistic awareness, cognitive strategy use, prior language-learning experience or increased motivation.

Demonstrating metalinguistic awareness as having a neutral to negative impact on writing may be illuminated by important details related to the educational context. Support for the influence of context on language choice is explicit in Herdina \& Jessner's (2002) dynamic model of multilingualism that indicates that (a) learners adapt their language choices to the environment and (b) make choices between languages based on perceived communicative needs. As it pertains to the broader educational context in this study, at the school and board levels, the only languages of instruction are French and English, with any maintenance of L1s and language (s) of origin remaining the responsibility of the parents outside of school hours. This limited focus is also evident in the FSL curriculum document that states that French must be the language of communication (Ontario Ministry of Education, 1998, p. 4) and reference to other languages is limited to English (p. 5). Similarly as it pertains to the classroom contexts, the teachers' language use or reference to languages in this study during the restricted observations was limited to French and English. The participants may have therefore adapted to the classroom environment and limited their language use to French and English leaving their language of origin for outside of the school context.

This limited view of languages as resources may also shed light on the positive impact of use of French (see Table 6) and the negative influence of metalinguistic awareness on writing as shown by the test results. Students may have chosen to adopt the focus of the surrounding educational context and limit their focus to French without 
knowingly drawing on their awareness of language (s) other than French to positively impact their FSL acquisition. Support for students' reliance on French without recognition of other language knowledge can be found in Jessner (2008a) who suggests that reliance on language awareness may be connected to need; therefore, if learners deem themselves to meeting with success learning FSL then they may not require the additional support of their other languages even in these early (A1) stages of language development. Having judged themselves as capable of meeting the perceived communicative needs of their FSL classes (Herdina \& Jessner, 2002), the learners may have chosen to limit their language of choice to French with limited use of English.

In addition to limiting their language use to French as being a possible factor influencing students' recognition of the potential for other language knowledge to prove beneficial, previous research suggests that students' use of prior language knowledge is dependent on its use being made explicit (e.g., Castelotti \& Moore, 2005; Singleton \& Aronin, 2007). In addition to making students aware of such knowledge, awareness of the potential for all prior language knowledge to impact Ln learning needs to be extended to teachers. In this case, although one teacher shared a common language (Punjabi) with her students in addition to French and English, she did not explicitly use that knowledge or make its potential usefulness explicit to her students during the observations. In this case, the absence of reference to languages, other than English and French, minimizes the potential for teacher multilingualism to be an advantage (Aronin \& Ó Laoire, 2003). In fact, Skuttnabb-Kangas (2000) goes so far as to suggest that teachers need to experience using their languages as resources prior to being able to encouraging their students to do so. That being the case, as Aronin \& Ó Laoire (2003) argue, teacher candidates would also benefit from explicit instruction to this effect during their teacher preparation programs. Applying these lessons to this context, it is possible that the multilingual teacher was unaware of the potential for Punjabi to positively impact her own and her students' Ln learning and thus, may have benefitted from explicit instruction on how to use her language knowledge to the benefit of her students.

Further to educational contexts, the broader provincial and Canadian context may have an influential role to play in students not automatically using their whole language repertoire as a resource in Ln learning. Provincial recognition and national status is limited to two languages-English and French. In Ontario and in the vast majority of Canada, official use of languages at elementary school is limited to those two languages. The formal valuing of two languages seen in this study, to the neglect of others, provides an example of the classroom replicating the broader society by limiting language use to those with official status. This Canadian context stands in contrast to the European context where the learning of Lns is commonplace. In fact, Jessner (2008b) claims that recognizing multilingualism across the curriculum has become a general trend in language teaching. This trend is supported by many European projects (i.e., European Centre for Modern Languages, Eurocom) that encourage raising language awareness. As noted in the Canadian contexts described above, attention to languages as resources has yet to extend to the Canadian context to the same degree. Canada in general and Ontario specifically, like other "English-dominant" regions (e.g., Australia as per Clyne, 2011; England as per Coyle, 2010), remains committed to supporting the development of English to the detriment of students learning other languages and/or maintaining their language (s) or origin/heritage language. Therefore as the rest of the world becomes increasing multilingual, with superior skills in English, there is potential for Canadian residents to become disadvantaged.

Findings from the ANOVAs and multiple regression analysis not only showed advantages for the IMM group, but also that the IMMs were the only group to be judged to have yielded positive predictive value. However, these advantages were not determined to be dependent on linguistic issues (L1s are not typologically close to French, proficiency) or cognitive factors (metalinguistic awareness and strategy use) or the socio-psychological factors of motivation nor the motivation to learn French to gain a Canadian identity for example, which suggests that the IMM group may have had unique qualities that remain unaccounted for. Aronin's (2004) research, however, offers some direction. Like Aronin (2004), who associated the positive attitudes of the immigrants in her study to their voluntary immigration to Israel, it is plausible that the IMM group in this study is positioned for success due to their families' choice to come to Canada. The context of immigration may also explain the finding that higher anxiety was associated with higher results for the IMM group. The IMM group may be less sure of their future potential in Canada and thus, strive to excel.

The above findings and subsequent discussion, however, need to be interpreted with caution. The questionnaire may not have been sensitive or detailed enough, which limits the applicability of the results. More research with carefully identified immigrant participant groups is required to better determine the impact of their metalinguistic awareness.

The aim of this research was to compare CBE, CBB and IMMs' FSL achievement and to investigate the possible influencing factors. The findings showed that the IMMs outperformed the CBEs on two measures and the CBB group outperformed the CBEs on one. The positive influencing factors were IMM group membership and use of French in and out of class. Given that other factors traditionally associated with superior performance did not correspond to FSL achievement, I looked to the context for other influential factors to uncover an educational and political context that limits language value to-at best, English and French. I suggest that such a context-subtractive where English is concerned and additive for French as it pertains to IMMs, creates pressure for immigrants that they use to their benefit to advance their FSL learning. Unfortunately, where that pressure- 
filled context may prove beneficial in the context of beginner FSL learning, it may prove detrimental to the maintenance of L1s and thus the multicompetence of the IMM group specifically as well as the potential for Canada to support the development of multilingual citizens more broadly.

\section{ACKNOWLEDGEMENT}

I would like to thank Stephanie Arnott, a research assistant on this project, for her comments on an earlier version of this paper.

\section{REFERENCES}

[1] Aronin, L. (2004). Multilinguality and emotions: Emotional experiences and language attitudes of trilingual immigrant students in Israel. Estudios de Sociolinguística, 5.1, 59-81.

[2] Aronin, L. \& O Laoire, (2003). Multilingual students' awareness of their language teacher's other languages. Language Awareness 12.3-4, 204-219.

[3] Balke-Aurell, G. \& Lindblad, T. (1983). Immigrant children and their languages. Gothenburg, Sweden: University of Gothenburg.

[4] Berthoud, A. (2003). Des pistes de recherché à explorer. In L. Mondada \& S. Pekarek Doehler (eds.), Plurilinguismes, mehrsprachifkeit, pluralingualism, enjeux indentitaires, socioculturels et éducatifs. Tübingen und Basel: Francke Verlag, 123129.

[5] Bialystok, E. (2001). Bilingualism in development: Language literacy and cognition. New York: Cambridge University Press.

[6] Bruno, G. (2001). Metacognitive reading awareness of trilingual readers in Barcelona. In J. Cenoz, B. Hufeisen \& U. Jessner (eds.), Looking beyond second language acquisition.' Studies in tri-and multilingualism. Tubingen: Stauffenburg Verlag, 137151.

[7] Castellotti, V. \& D. Moore (2005). Des politiques linguistiques aux classes de langue : représentations et pratiques du plurilinguisme. In M.-A. Mochet \& al. (eds.), Plurilinguisme et apprentissages. Mélanges Daniel Coste. Collection Hommages (Special Issue), ENS-Éditions, Lyon, 103-107.

[8] Cazden, C. R. (1974). Play with language and metalinguistic awareness: One dimension of language experience. The Urban Review, 7, 28-29.

[9] Cenoz, J. \& Valencia, J. (1994). Additive trilignualism: Evidence from the Basque country. Applied Psycholinguistics, 15, 195207.

[10] Centre international d'études pédagogiques. (2012). DELF A1 Primaire. Retrieved from: http://www.ciep.fr/en/delfdalf/exemples-de-sujets-DELF-Prim.php (accessed 23/7/2013).

[11] Clyne, M. (2011). Three is too many in Australia. In C. L. Hélot, M. (Ed.), Language policy for the multilingual classroom. Toronto, Ontario, Canada: Multingualism Matters, 174-187.

[12] Clyne, M., Hunt, C., \& Isaakidis, T. (2004). Learning a community language as a third language. The International Journal of Multilingualism, 1.1, 33-52.

[13] Coyle, D (2010). Language Pedagogies Revisited: alternative approaches for integrating language learning, language using and intercultural understanding in Miller, J., Kostogriz, A and Gearon, M (eds.), Culturally and Linguistically Diverse Classrooms: New Dilemmas for Teachers Ontario: Multilingual Matters, 172-196.

[14] Cook, V. (1995). Multi-competence and the learning of many languages. Language, Culture and Curriculum, 8(2), 93-98. doi: $10.1080 / 07908319509525193$

[15] Cummins, J. (1979). Linguistic interdependence and the educational development of bilingual children. Review of Educational Research, 49, 222-251. doi: 10.3102/00346543049002222.

[16] De Angelis, G. (2007). Third or additional language acquisition. Toronto, Ontario, Canada: Multilingualism Matters.
[17] Eurocom (2003). Eurocom Rom. Retrieved

from: http://www.eurocomcenter.eu/index2.php?lang=uk\&main_id=3\&sub_id=3\&datei=konzept.htm (accessed 23/7/2013).

[18] Geldersen, A. S., R; Glopper, K; Hulstijin, J.; Snellings, P.; Simis, A.; Stevensen, M. (2003). Roles of linguistic knowledge, metacognitive knowledge and processing speed in L3, L2 and L1 reading comprehension: A structural equation modelling approach. International journal of bilingualism, 7.1, 7-25.

[19] Gibson, M. \& Hufeisen, B. (2003). Investigating the role of prior foreign language knowledge: Translating from an unknown into a known foreign language. In J. Cenoz, B. Hufeisen; \& U. Jessner, (eds.), The multilingual lexicon. Toronto, Ontario, Canada: Multilingualism Matters, 87-102

[20] Hart, D., Lapkin, S., \& Swain, M. (1988). Ethnolinguistic minorities: Tracking success in an exemplary English-French immersion program. Toronto, Ontario, Canada: MLC, OISE/UT.

[21] Herdina, P. \& Jessner, U. (2002). A Dynamic Model of Multilingualism: Perspectives of Change in Psycholinguistics. Toronto, Ontario, Canada: Multilingualism Matters.

[22] Ibarraron, A., Lasagabaster, D., Manuel Sierra, Juan. (2008). Multilingualism and language attitudes: Local versus immigrant students' perceptions. Language Awareness, 17.4, 326-341.

[23] Jessner, U. (1999). Metalinguistic Awareness in Multilinguals: Cognitive Aspects of Third Language Learning. Language Awareness, 8.3 \& 4, 201-209.

[24] Jessner, U. (2008a). A DST Model of Multilingualism and the Role of Metalinguistic Awareness. Modern Language Journal, 92(2), 270-283. doi: 10.1111/j.1540-4781.2008.00718.x.

[25] Jessner, U. (2008b). Teaching third languages: Findings, trends and challenges. Language Teaching, 41.1, 15-56.

[26] Kellerman, E. (1978). 'Giving learners a break: native language intuitions as a source of predictions about transferability'. Working Papers on Bilingualism 15: 59-92. 
[27] Kemp, C. (2007). Strategic Processing in Grammar Learning: Do Multilinguals Use More Strategies? International Journal of Multilingualism, 4.4, 241-261. doi: 10.2167/ijm099.0.

[28] Lasagabaster, D. (1998). The threshold hypothesis applied to three languages in contact in school. International Journal of bilingual education and bilingualism, 1.2, 119-132.

[29] Lasagabaster, D. (2001). The effect of knowledge about the L1 on foreign language skills and grammar. Bilingual Education and Bilingualism, 4.5, 310-331.

[30] Moore, D. (2006). Plurilingualism and strategic competence in context. The International Journal of Multilingualism, 3.2, 125138.

[31] Ontario Ministry of Education. (1998). The Ontario curriculum: French as a second language: Core French grades $4-8$. Toronto, Ontario, Canada: Ontario Ministry of Education.

[32] Perales, J., \& Cenoz, J. (2002). The Effect of Individual and Contextual Factors in Adult Second-Language Acquisition in the Basque Country. Language, Culture and Curriculum, 15(1), 1-15. doi: 10.1080/07908310208666629.

[33] Peyer, E., Kaiser, I., \& Berthele, R. (2010). The multilingual reader: advantages in understanding and decoding German sentence structure when reading German as an L3. International Journal of Multilingualism, 7.3, 225-239. doi: $10.1080 / 14790711003599443$.

[34] Singleton, D. A., Larissa. (2007). Multiple language learning in the light of the theory of affordances. Innovation in language learning and teaching, 1.1, 83-96.

[35] Skutnabb-Kangas, Tove. (2000). Linguistic human rights and teachers of English. In Hall, Joan Kelly \& Eggington, William G. (eds.), The Sociopolitics of English Language Teaching. Clevedon: Multilingual Matters, 22-44.

[36] Statistics Canada. (2006). Immigration in Canada: A Portrait of the Foreign-born Population, 2006 Census: Portraits of major metropolitan centres. Retrieved from: http://www12.statcan.ca/census-recensement/2006/as-sa/97-557/p24-eng.cfm (accessed 23/7/2013).

[37] Ushioda, E. and Dörnyei, Z. (2012). Motivation. In S. Gass and A. Mackey (eds.), The Routledge Handbook of Second Language Acquisition. Abingdon: Routledge, 396- 409.

Callie Mady is an associate professor at Nipissing University in the Schulich School of Education. She holds a PhD from OISE of the University of Toronto with a focus on second language education. Her research interests include French as a second language education and multilingual language acquisition.

\footnotetext{
${ }^{\mathrm{i}}$ In Canada, French is referred to as a second language in "English-dominant" regions due to its status as the second official language of Canada. In this study, FSL is used with the knowledge that it is an Ln for many learners.

${ }^{\text {ii }}$ While it was not the explicit focus of this paper, I would be remised if I did not acknowledge the disadvantage identified for boys and students in need of learning support, and the highly substantial advantage of being in one school rather than the other.
} 